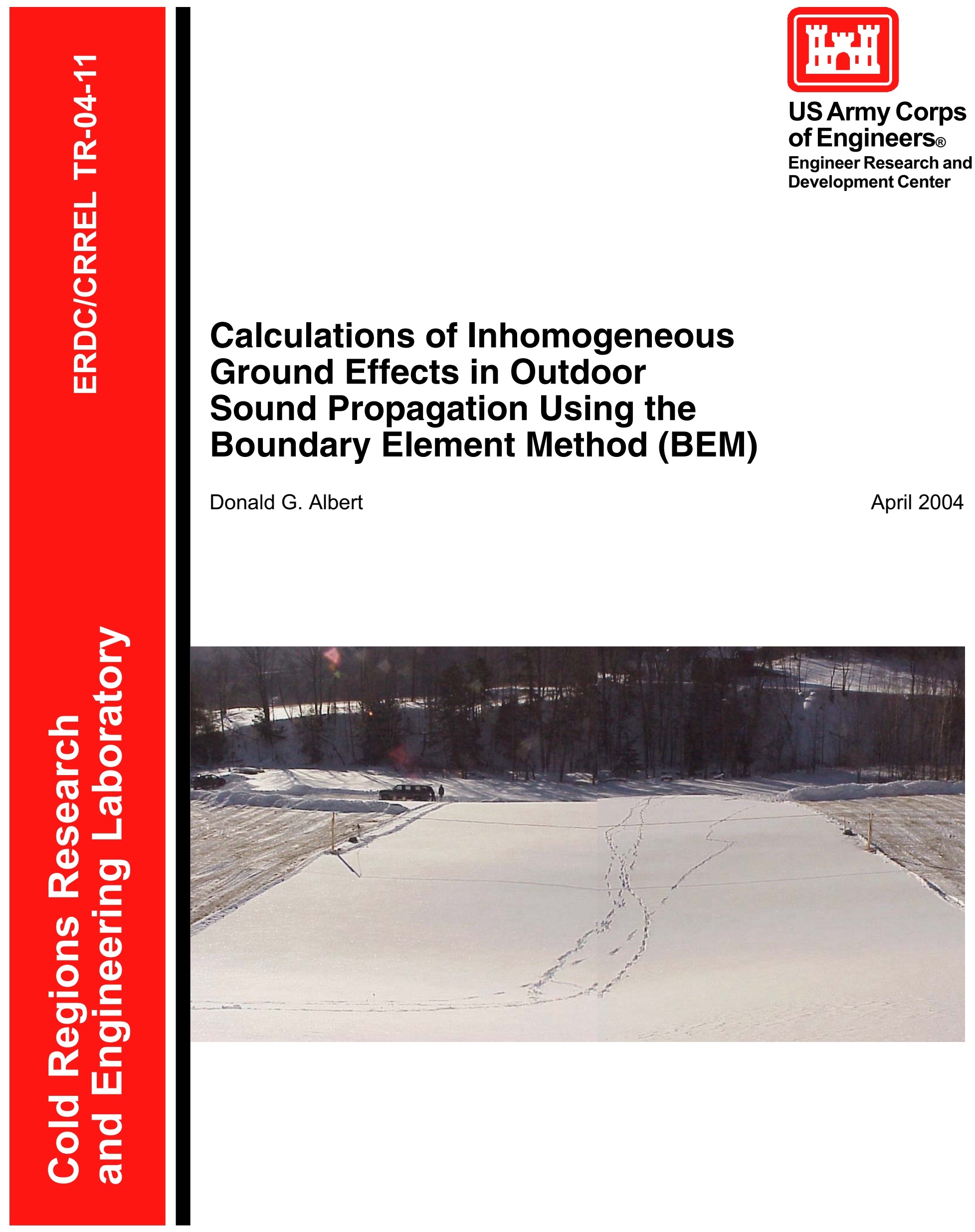


Front cover: Composite photograph of the test site used to collect measurement data to verify the Boundary Element Method for acoustic propagation over inhomogeneous ground. By removing the natural snow cover, the surface impedance in specific areas is greatly increased. Here the remaining snow patch is 30 meters wide, and contains a few wild deer tracks. 


\section{Calculations of Inhomogeneous Ground Effects in Outdoor Sound Propagation Using the Boundary Element Method (BEM)}

Donald G. Albert

Approved for public release; distribution is unlimited. 


\section{ABSTRACT}

This report summarizes the results of a study to calculate the effect of inhomogeneous ground impedance on acoustic wave propagation. The boundary element method was used to investigate the effect of snow or bare ground patches along the acoustic propagation path. This method can be used to calculate the effect of inhomogeneities in the propagation medium with a relatively small computational effort compared to many other methods (for example, the finite difference method). The boundary element method is first verified by showing agreement with a published result, and then shown to give good agreement with experimental measurements.

DISCLAIMER: The contents of this report are not to be used for advertising, publication, or promotional purposes. Citation of trade names does not constitute an official endorsement or approval of the use of such commercial products. All product names and trademarks cited are the property of their respective owners. The findings of this report are not to be construed as an official Department of the Army position unless so designated by other authorized documents. 


\section{CONTENTS}

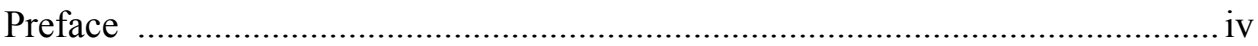

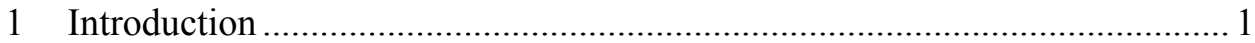

2 The Boundary Element Method (BEM) …................................................. 2

Open BEM Code and Modifications ………............................................. 5

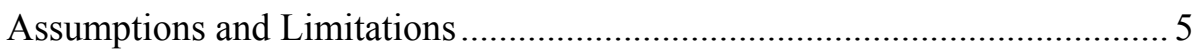

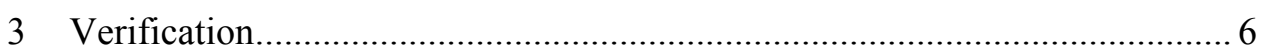

4 Results for Inhomogeneous Ground Impedance .......................................... 7

Examples for Snow Covers .......................................................................... 7

Comparison with Measured Data .............................................................. 7

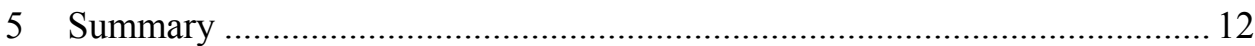

\section{ILLUSTRATIONS}

Figure 1. (Top) Geometry in the generic boundary element method. The boundary $\Gamma$ can have any desired shape. (Bottom) Geometry for the snow cover calculations in this paper................................................................. 3

Figure 2. Verification of the MATLAB Open BEM code results by comparison

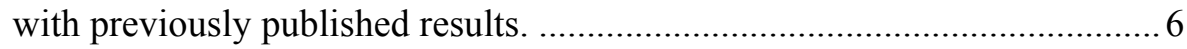

Figure 3. Excess attenuation calculated for sound propagation over a

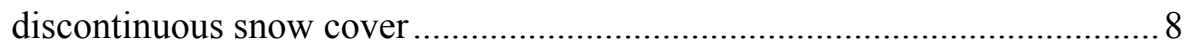

Figure 4. Excess attenuation calculated for sound propagation over discontinuous snow covers of various dimensions............................................... 9

Figure 5. Measured excess attenuation for sound propagation over homogeneous and inhomogeneous ground ......................................................... 10

Figure 6 . Theoretical prediction of excess attenuation for sound propagation over homogeneous and inhomogeneous ground, calculated using the BEM. 


\section{PREFACE}

This report was prepared by Dr. Donald G. Albert, Geophysicist, Geophysical Sciences Division, Cold Regions Research and Engineering Laboratory (CRREL), U.S. Army Engineer Research and Development Center (ERDC), Hanover, New Hampshire.

The experiments were conducted with the assistance of Dave Carbee, Steve Decato, Frank Perron, and Dr. Joyce Nagle under AT24 work unit "Seismic and Acoustic Wave Propagation in Cold Regions." The author thanks Leon Stetson for use of the field site; Dr. Peter Juhl, University of Southern Denmark, for providing the Open BEM code; and Dr. Susanna Quiros y Alpera and others for their contributions to this code. Funding for these calculations was provided by Dr. Mark Moran under AT42 project "Support to Acoustic Propagation Modeling." Technical reviews were provided by Dr. Tom Anderson and Dr. Keith Wilson. This work is supported by the Directorate of Research and Development, U.S. Army Corps of Engineers.

The Commander of the Engineer Research and Development Center is Colonel James R. Rowan, EN. The Director is Dr. James R. Houston. 


\title{
Calculations of Inhomogeneous Ground Effects in Outdoor Sound Propagation Using the Boundary Element Method (BEM)
}

\author{
DONALD G. ALBERT
}

\section{INTRODUCTION}

An understanding of the interaction of sound energy with the ground is important in predicting noise propagation through the atmosphere (Embleton et al. 1976, Embleton et al. 1983, Attenborough 1992, Embleton 1996, Sutherland and Daigle 1997). It affects predictions of traffic, industrial, and blasting noise levels, and is important in mitigating and assessing environmental impacts of military activities. In realistic situations, noise or sound often propagates horizontally over ground with varying surface properties, including vegetation, paving, etc. In this study, the boundary element method was used to study sound propagation over laterally inhomogeneous ground impedance. General effects and computational behaviors are investigated for simple cases, and the method is compared to measured data. 


\section{THE BOUNDARY ELEMENT METHOD (BEM)}

The boundary element method has been frequently used to solve problems in acoustics (Jensen et al. 1994, Estorff 2000, Xu 2001). Recently, the method has been applied to traffic noise problems, allowing the effect of different ground surfaces (paved roads or natural ground cover), topography, and various screens designed to mitigate noise to be evaluated (Hothersall et al. 1991, Hothersall and Harriott 1995, Chandler-Wilde 1997, Defrance and Premat 2001). ChandlerWilde (Chandler-Wilde 1997) has presented a thorough review of the method's application to outdoor sound problems.

In this section we briefly summarize the boundary element method, following Chandler-Wilde (Chandler-Wilde 1997). This reference and the book by $\mathrm{Wu}$ (Wu 2000, Chapters 2 and 3) both provide derivations of the BEM equations, which are not repeated here. In a homogeneous space, the Helmholtz equation is

$$
\nabla^{2} p+k^{2} p=0
$$

where $p$ is the pressure, $k=\omega / c$ is the wavenumber, $\omega$ the radial frequency, and $c$ the acoustic wave in air. For a locally reacting porous medium on the ground, the impedance boundary condition can be written as

$$
\frac{\partial p}{\partial n}=i k p \beta
$$

where $\beta=1 / Z$ ( $=0$ for a rigid surface) is the admittance normalized to air. ( $Z$ is the impedance.) The Sommerfeld radiation condition is also specified. In two dimensions with a line source, the solution of Equation 1 is

$$
p=\frac{-i}{4} H_{0}^{(1)}(k R)
$$

where $R$ is the source-receiver distance and $H_{0}^{(1)}$ the Hankel function of the first kind. Here, $e^{-i \omega t}$ time dependence has been assumed. Chandler-Wilde shows that the same methods used to solve the two-dimensional case presented here can also be used to solve three-dimensional problems for a point source; of course, these problems would require much more computational effort because of the greater number of points in the three-dimensional space. 


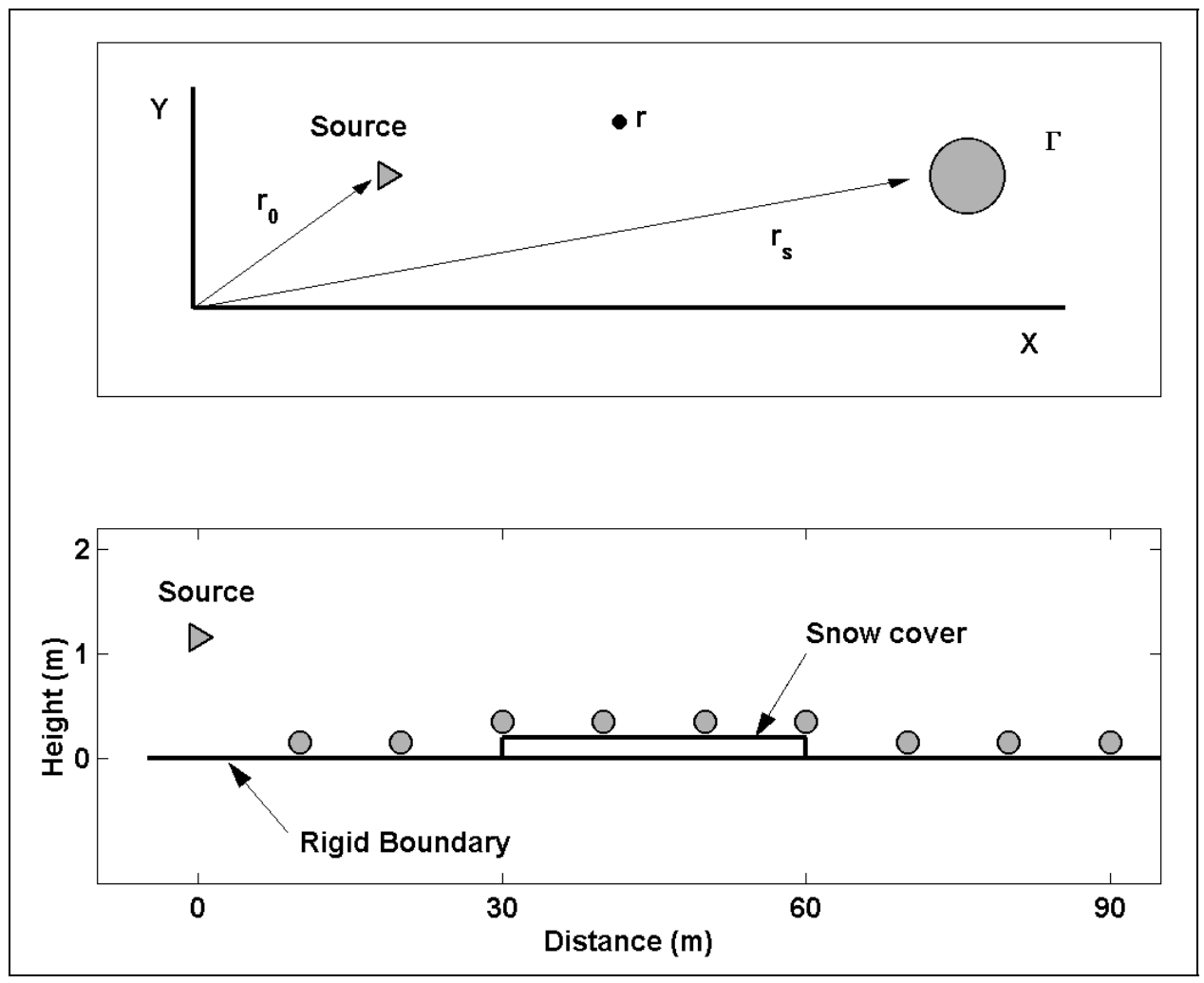

Figure 1. (Top) Geometry in the generic boundary element method. The boundary $\Gamma$ can have any desired shape. (Bottom) Geometry for the snow cover calculations in this paper.

The boundary integral equation can be derived from the Helmholtz equation by application of Green's second identity. For a source at $\boldsymbol{r}_{\mathbf{0}}$ and a scattering body with boundary $\Gamma$ and admittance $\beta$, the resultant pressure at any point $\boldsymbol{r}$ external to the body (Fig. 1) is given by

$$
b(r) p\left(r, r_{0}\right)=G\left(r, r_{0}\right)+\int_{\Gamma}\left[\frac{\partial G\left(r_{s}, r\right)}{\partial n\left(r_{s}\right)}-i k \beta G\left(r_{s}, r\right)\right] p\left(r_{s}, r\right) d S\left(r_{s}\right) .
$$

This is Chandler-Wilde's equation (1). The coefficient $b(r)$ is a "receiver boundary location coefficient" with a value of 1 if $\boldsymbol{r}$ is not on the boundary, and a value of $1 / 2$ if $\boldsymbol{r}$ is on a flat boundary. $G$ is a solution for the pressure without the scattering object. For example, in free space, $G$ is just the solution given by Equation 3. Equation 4 shows that the pressure can be calculated from the pres- 
sure values on the surface of the scattering body, and is the fundamental equation used in BEM calculations.

For outdoor sound propagation with a flat, homogeneous finite impedance boundary at $y=0$, Equation 4 still holds if we take $G$ to represent the pressure when the ground is present. Chandler-Wilde and Hothersall (Chandler-Wilde and Hothersall 1995) have shown that this solution is

$$
G\left(r, r_{0}\right)=-\frac{i}{4} H_{0}^{(1)}(k R)-\frac{i}{4} H_{0}^{(1)}\left(k R^{\prime}\right)+B\left(r, r_{0}\right)
$$

where $R^{\prime}$ is the image source $\left(x_{0},-y_{0}\right)$ to $r$ distance. The first two terms are the direct ray and the ray from the image source. The term $B$ gives the contribution of the boundary, including the specular reflection and any surface wave terms that might be present (depending on the boundary material parameters). It contains the boundary loss term used in other formulations of the problem. If the boundary is rigid, $B=0$ and the perfect reflection is included in the second term of Equation 5. Equations 4 and 5 are used for the calculations in this paper.

Equation 4 is solved numerically by dividing the boundary $\Gamma$ into discrete elements (usually the element length $<$ wavelength/5), assuming the pressure at the boundary element from a source at $r 0, p($-element, $r 0)$, is constant over the entire element, and solving for the pressures over the boundary $\Gamma$. Then Equation 4 with the known pressures on the boundary is solved to find the pressure at any other desired point. Thus the boundary of a snow cover (as shown in the bottom panel of Figure 1) is subdivided into a series of small elements, and the above procedure is used to find the acoustic pressure field with the snow cover present. $\mathrm{Wu}(\mathrm{Wu} 2000)$ discusses various discretization schemes; in acoustic problems a simple linear element approximation is usually used. While non-unique solutions exist at the resonant frequencies of the scattering objects, these ambiguities are easily resolved by calculating a few interior points, a procedure termed the CHIEF method (Wu 2000).

A primary advantage of the BEM method is that only the scattering objects need to be discretized, instead of the full propagation space as for the full finite difference or finite element methods, offering a large savings in computational effort. The cost of BEM calculations is dependent on the size of the scatterers with respect to the wavelength, so it is most efficient where the scatterers are relatively small. Because the element size depends on the wavelength, doubling the frequency will double the computation time. 


\section{Open BEM Code and Modifications}

There are many codes available for solving acoustic problems using BEM. For example, Fortran codes are provided in books (Wu 2000) and at various Web sites. For this paper, the author used a code called Open BEM that was written in Matlab. ${ }^{*}$ Although an interpreted language, and thus slow compared to a compiled language such as Fortran, Matlab is much easier to program and provides good visualization tools. This Matlab code has been used to solve many acoustic problems, including previous calculations in outdoor sound propagation (Quiros y Alpera and Jacobsen 2002).

The Open BEM code provides a solution method for two-dimensional problems using Equations 4 and 5 discussed above. This code has been modified by the author to use boundary admittance calculated from Attenborough's ground impedance model (Attenborough 1985) instead of the Delany Bazley model (Delaney and Bazley 1970) as the latter model does not work well for snow. Currently, the Attenborough model is implemented only as a lookup table, with the admittance values actually calculated separately using a Fortran code.

\section{Assumptions and Limitations}

For the problems discussed in this report, a homogeneous atmosphere is assumed. Because the ground at the experimental site was frozen, we assume that it is rigid in the model, and that the snow-cover properties are homogeneous. Finally, we restrict the calculations to a two-dimensional geometry. All of these assumptions can be relaxed in the boundary element method, but at the cost of increased computational time.

\footnotetext{
* Personal communication, P. Juhl, University of Southern Denmark, 2001.
} 


\section{VERIFICATION}

To become familiar with the Open BEM code and check its operation, an example taken from the published literature produced by authors not associated with Open BEM was calculated. The example is a barrier above a finite impedance plane with a flow resistivity of $250 \mathrm{kN} \mathrm{s} \mathrm{m}^{-4}$. The published result (Hothersall et al. 1991) and the geometry are shown in Figure 2, along with the result calculated using the Open BEM code. The calculations agree with the published results. This calculation took about 4.5 minutes on a $2 \mathrm{GHz}$ personal computer.

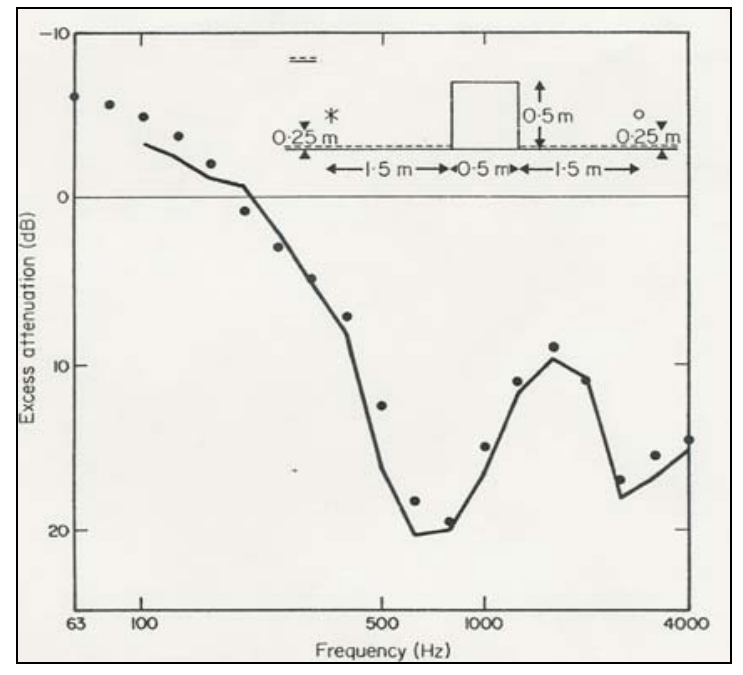

a. Published BEM result (from Hothersall et al. 1991) for the geometry shown on the graph. Dots are BEM calculations, lines are measurements.

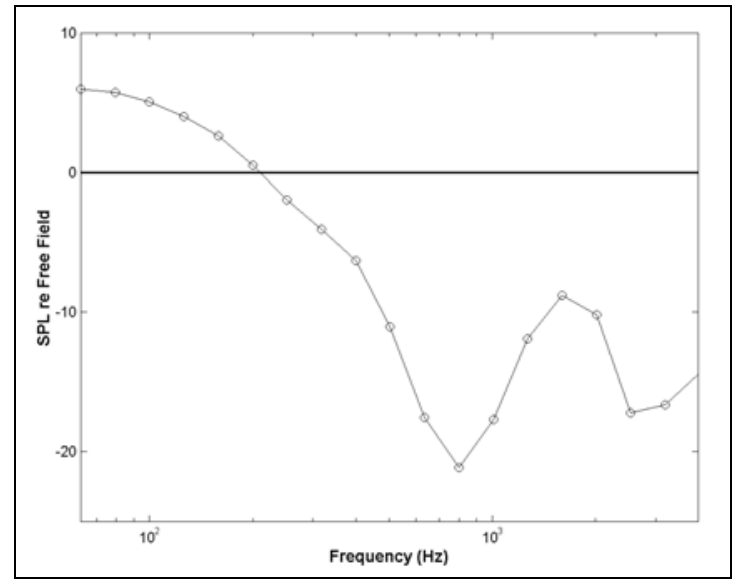

b. Results of the current Open BEM code for the same situation.

Figure 2. Verification of the MATLAB Open BEM code results by comparison with previously published results. 


\section{RESULTS FOR INHOMOGENEOUS GROUND IMPEDANCE}

In this section the results of the BEM calculations are presented. Since the ground is usually frozen during the winter, in each case we assume that the ground is rigid (thus $B=0$ in Equation 5). A snow cover with a depth of $20 \mathrm{~cm}$ and an effective flow resistivity of $7000 \mathrm{~Pa} \mathrm{~m}^{-2} \mathrm{~s}$ is included as shown in Figure 1 , bottom. This snow cover is treated as a scattering object placed on top of the rigid ground surface, and the effect of changing the dimensions and location of the snow cover is studied. A line source is located $1 \mathrm{~m}$ above the surface at zero distance. The excess attenuation, defined as the signal level difference from the level in free space (that is, without a ground surface or any scatterers present) at the same distance, is shown in all cases.

\section{Examples for Snow Covers}

Figure 3 shows an example of the excess attenuation calculated using BEM for propagation over a discontinuous snow cover. In this example, the snow cover is located 30 to $60 \mathrm{~m}$ away from the source. The results show an excess attenuation of $+6 \mathrm{~dB}$ (that is, enhancement by a factor of two) for distances of 0 to $30 \mathrm{~m}$ from the source at all frequencies, representing the reflection from the rigid boundary. When the snow layer is reached, the excess attenuation becomes greater, with a value of about $0 \mathrm{~dB}$ for frequencies below $100 \mathrm{~Hz}$ and reaching $-30 \mathrm{~dB}$ for higher frequencies. This frequency-dependent attenuation has been observed experimentally and is one of the main characteristics of propagation over homogeneous snow covers (Albert and Orcutt 1990). The low-pass filtering effect of the snow remains as the propagation continues over bare ground beyond the snow layer. This calculation took five minutes for the 19 frequencies shown in Figure 3.

Additional examples of the snow-cover effect, with the snow at different locations along the propagation path, are shown in Figure 4. The excess attenuation is always greater over the snow cover, but remains large at high frequencies when the propagation continues over rigid ground. The computation time for these examples ranged from 5 to 34 minutes, depending on the snow-cover length (30 to $90 \mathrm{~m})$.

\section{Comparison with Measured Data}

An experiment was conducted to investigate homogeneous ground outdoors using a natural snow cover (Albert 2000). A blank pistol, held $1 \mathrm{~m}$ above the ground surface, was used as the source of the acoustic waves, which were digi- 
tally recorded by a microphone at the ground or snow surface $60 \mathrm{~m}$ away from the source. This measurement was repeated with four different ground conditions between the source and receiver. If we let $\mathrm{S}$ represent propagation over $30 \mathrm{~m}$ of snow, and $\mathrm{G}$ propagation over $30 \mathrm{~m}$ of plowed ground, the configurations (reading from source to receiver) were SS (undisturbed snow), SG (snow followed by plowed ground), GS (ground then snow), and GG (all plowed ground).

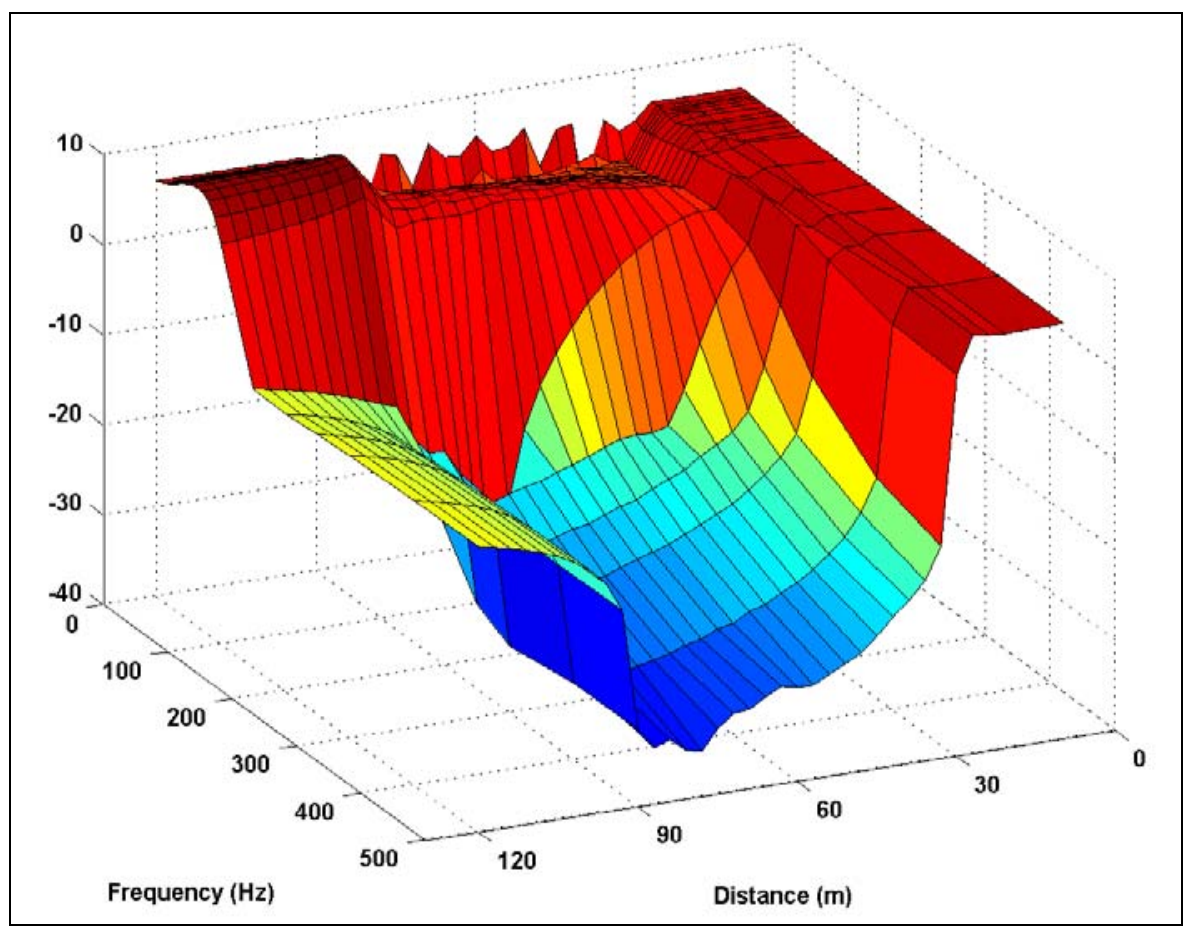

Figure 3. Excess attenuation calculated for sound propagation over a discontinuous snow cover. The axis on the left is the frequency $(\mathrm{Hz})$ while the axis on the right is the distance $(\mathrm{m})$. The snow cover, located between $30 \mathrm{~m}$ and $90 \mathrm{~m}$ from the source, was $20 \mathrm{~cm}$ deep and had an effective flow resistivity of $7000 \mathrm{~Pa} \mathrm{~m}^{-2} \mathrm{~s}$.

The pistol shot waveforms were Fourier transformed and the transform corresponding to the GG case, representing a rigid ground surface, was adjusted to $+6 \mathrm{~dB}$ to account for the source strength, receiver response, and geometric spreading of the wave. The same adjustment was applied to the other transforms, resulting in the excess attenuation measurements shown in Figure 5. As expected, the excess attenuation is large for higher frequencies traveling over snow, with the largest excess attenuation occurring for the longer path over snow (SS). In these measurements, the attenuation increases for frequencies of $50 \mathrm{~Hz}$ and above. 


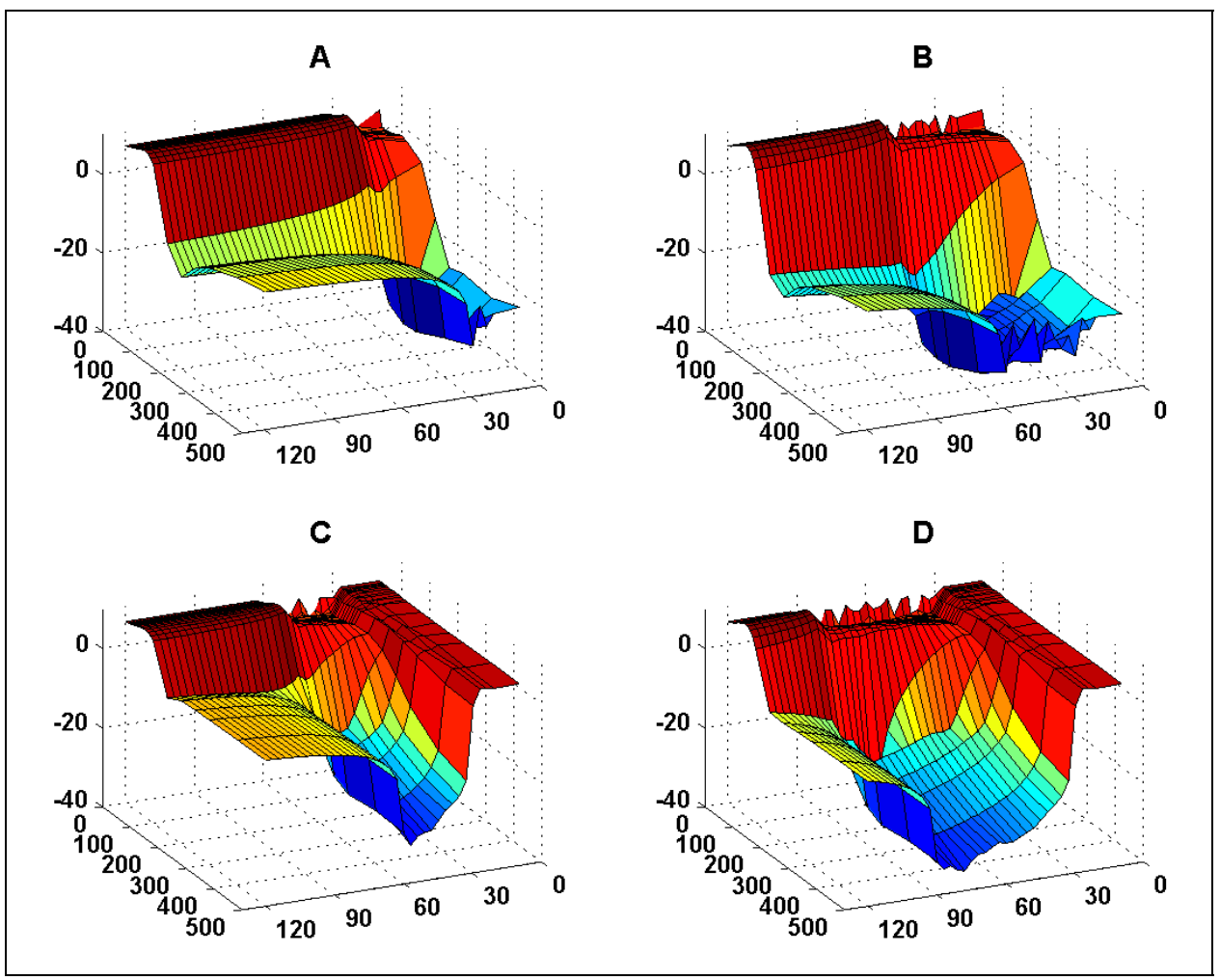

Figure 4. Excess attenuation calculated for sound propagation over discontinuous snow covers of various dimensions. For each plot, the axis on the left is the frequency $(\mathrm{Hz})$ while the axis on the right is the distance $(\mathrm{m})$. The snow cover was located between $-30 \mathrm{~m}$ and $30 \mathrm{~m}(\mathrm{~A}),-30 \mathrm{~m}$ and $60 \mathrm{~m}$ (B), $+30 \mathrm{~m}$ and $60 \mathrm{~m}(\mathrm{C})$, and $30 \mathrm{~m}$ and $90 \mathrm{~m}(\mathrm{D})$.

Theoretical predictions for these ground situations and geometries were calculated using the boundary element method and the results are shown in Figure 6 . In these calculations the snow cover thickness was $20 \mathrm{~cm}$ and the effective flow resistivity was $7000 \mathrm{~Pa} \mathrm{~m}^{-2} \mathrm{~s}$. Although some of the details are different (for example, the theoretical excess attenuation starts to increase at 100 $\mathrm{Hz}$ instead of $50 \mathrm{~Hz}$ ), there is good general agreement between the measured and theoretical excess attenuations for these four situations. (The low apparent measured attenuation for frequencies above $500 \mathrm{~Hz}$ is caused by a low signal-to-noise ratio from the very low output of the source at these frequencies.) Improved agreement could probably be obtained by modifying the assumed snow parameters, in particular by lowering the assumed excess flow resistivity and by increasing the assumed snow depth. (The average measured snow depth was 28 $\mathrm{cm}$.) 


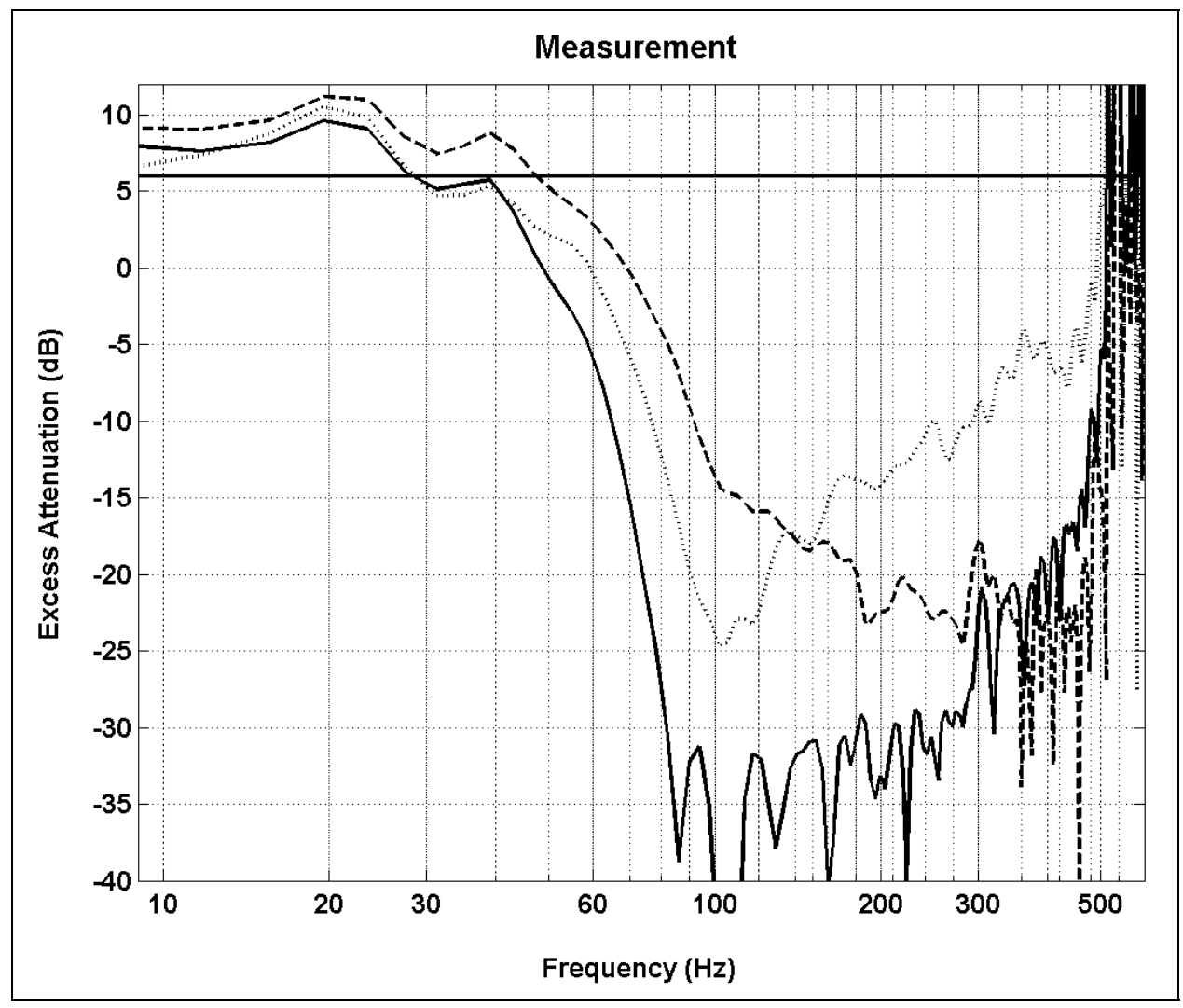

Figure 5. Measured excess attenuation for sound propagation over homogeneous and inhomogeneous ground. Cases SS (solid line), GS (dashed line), and SG (dotted line) are shown normalized to case GG (solid horizontal line at $+6 \mathrm{~dB})$. 


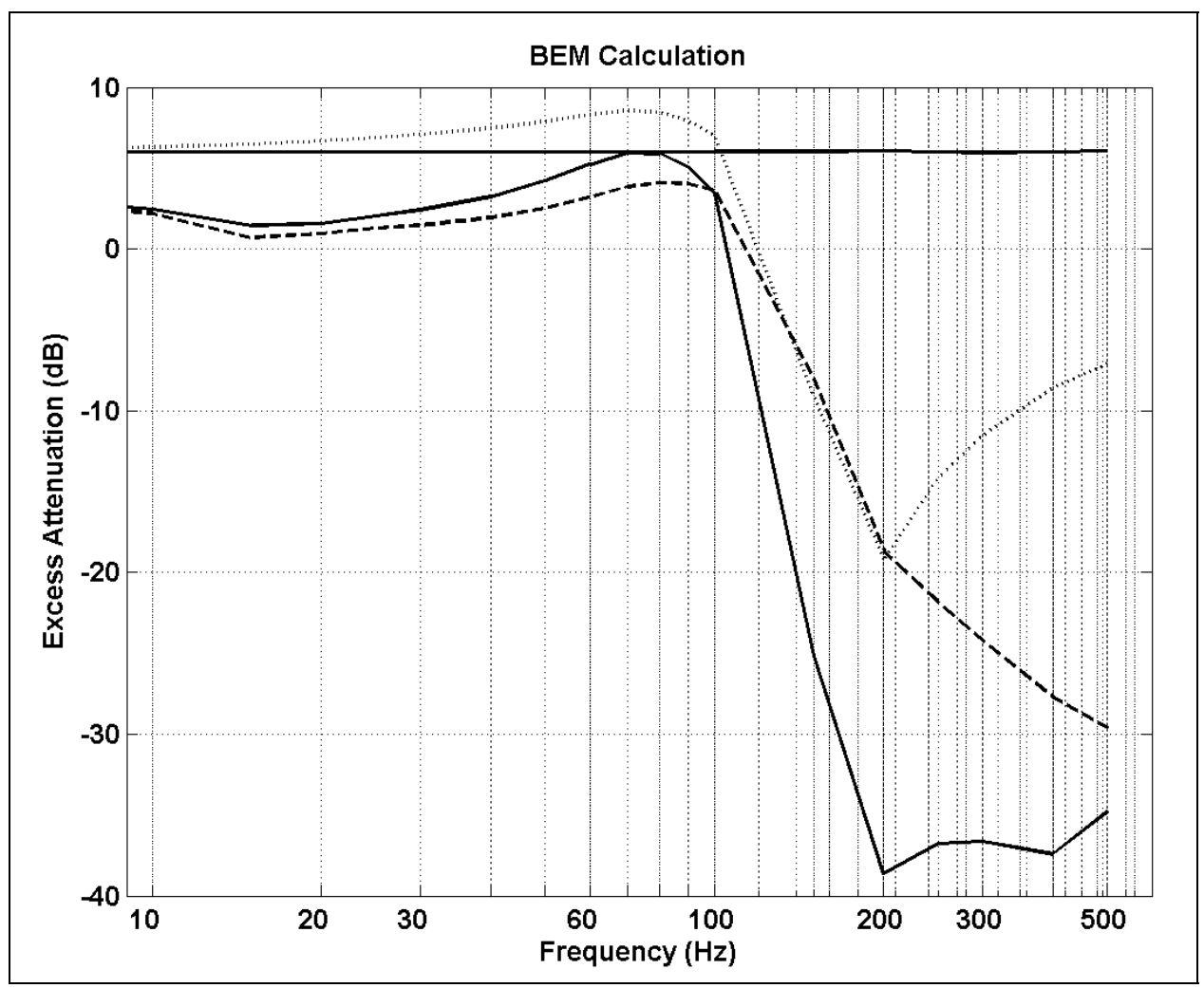

Figure 6. Theoretical prediction of excess attenuation for sound propagation over homogeneous and inhomogeneous ground, calculated using the BEM. Cases SS (solid line), GS (dashed line), and SG (dotted line) are shown normalized to case GG (solid horizontal line at $+6 \mathrm{~dB}$ ). 


\section{SUMMARY}

This report has demonstrated that the Open BEM code gives results in agreement with other BEM codes and with experimental measurements. The code provides a rapid, easy to use, accurate tool for calculating the effect of inhomogeneous ground conditions and scattering from barriers on outdoor sound propagation. 


\section{REFERENCES}

Albert, D.G. (2000) Acoustic pulse propagation over laterally inhomogeneous ground. Journal of the Acoustical Society of America, 108: 2650.

Albert, D.G., and J.A. Orcutt (1990) Acoustic pulse propagation above grassland and snow: Comparison of theoretical and experimental waveforms. Journal of the Acoustical Society of America, 87: 93-100.

Attenborough, K. (1985) Acoustical impedance models for outdoor ground surfaces. Journal of Sound and Vibration, 99: 521-544.

Attenborough, K. (1992) Ground parameter information for propagation modeling. Journal of the Acoustical Society of America, 92: 418-427.

Chandler-Wilde, S.N. (1997) The boundary element method in outdoor noise propagation. Proceedings, Institute of Acoustics, 19 (Part 8): 27-50.

Chandler-Wilde, S.N., and D.C. Hothersall (1995) Efficient calculation of the Green function for acoustic propagation above a homogeneous impedance plane. Journal of Sound and Vibration, 180: 705-724.

Defrance, J., and E. Premat (2001) Application of two impedance discontinuity models to real road traffic noise in cases in inhomogeneous air conditions. In 17th International Congress of Acoustics, Rome, Italy.

Delaney, M.E., and E.N. Bazley (1970) Acoustical properties of fibrous absorbent materials. Applied Acoustics, 3: 105-116.

Embleton, T.F.W. (1996) Tutorial on sound propagation outdoors. Journal of the Acoustical Society of America, 100: 31-48.

Embleton, T.F.W., J.E. Piercy, and N. Olson (1976) Outdoor sound propagation over ground of finite impedance. Journal of the Acoustical Society of America, 59: 267-277.

Embleton, T.F.W., J.E. Piercy, and G.A. Daigle (1983) Effective flow resistivity of ground surfaces determined by acoustical measurements. Journal of the Acoustical Society of America, 74: 1239-1244.

Estorff, O.V., Ed. (2000) Boundary Elements in Acoustics: Advances and Applications. Boston: WIT Press, $476 \mathrm{p}$.

Hothersall, D.C., and J.N.B. Harriott (1995) Approximate models for sound propagation above multi-impedance boundaries. Journal of the Acoustical Society of America, 97: 918-926. 
Hothersall, D.C., S.N. Chandler-Wilde, and M.N. Hajmirzae (1991) Efficiency of single noise barriers. Journal of Sound and Vibration, 146: 303-322.

Jensen, F.B., W.A. Kuperman, M.B. Porter, and H. Schmidt (1994) Computational Ocean Acoustics. New York: American Institute of Physics.

Quiros y Alpera, S., and F. Jacobsen (2002) Validation of a model for sound propagation over non-flat terrain using BEM. In International Conference on Sound and Vibration, Orlando, Florida.

Sutherland, L.C., and G.A. Daigle (1997) Atmospheric sound propagation. In Encyclopedia of Acoustics (M.J. Crocker, Ed.), 341-365. New York: John Wiley \& Sons, Inc.

Wu, T.W., Ed. (2000) Boundary Element Acoustics: Fundamentals and Computer Codes. Boston: WIT Press, 238 p.

Xu, S.Z. (2001) The Boundary Element Method in Geophysics. Tulsa, Oklahoma: Society of Exploration Geophysicists, 217 p. 


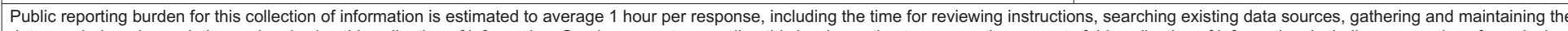

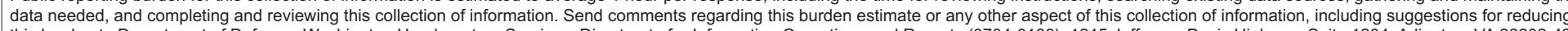

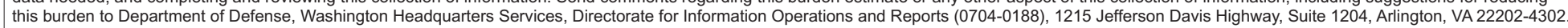

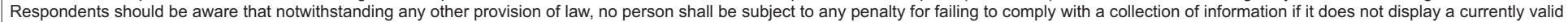
OMB control number. PLEASE DO NOT RETURN YOUR FORM TO THE ABOVE ADDRESS.
1. REPORT DATE (DD-MM-YY)
April 2004
4. TITLE AND SUBTITLE
Calculations of Inhomogeneous
Ground Effects in Outdoor
Sound Propagation Using the
Boundary Element Method (BEM)

\section{REPORT TYPE}

Technical Report

3. DATES COVERED (From - To)

5a. CONTRACT NUMBER

5b. GRANT NUMBER

5c. PROGRAM ELEMENT NUMBER

6. AUTHOR(S)

5d. PROJECT NUMBER

Donald G. Albert

5e. TASK NUMBER

5f. WORK UNIT NUMBER

7. PERFORMING ORGANIZATION NAME(S) AND ADDRESS(ES)

8. PERFORMING ORGANIZATION REPORT

U.S. Army Engineer Research and Development Center

Cold Regions Research and Engineering Laboratory

72 Lyme Road

Hanover, NH 03755-1290

ERDC/CRREL TR-04-11

9. SPONSORING/MONITORING AGENCY NAME(S) AND ADDRESS(ES)

10. SPONSOR / MONITOR'S ACRONYM(S)

11. SPONSOR / MONITOR'S REPORT NUMBER(S)

\section{DISTRIBUTION / AVAILABILITY STATEMENT}

Approved for public release; distribution is unlimited.

Available from NTIS, Springfield, Virginia 22161.

13. SUPPLEMENTARY NOTES

\section{ABSTRACT}

This report summarizes the results of a study to calculate the effect of inhomogeneous ground impedance on acoustic wave propagation. The boundary element method was used to investigate the effect of snow or bare ground patches along the acoustic propagation path. This method can be used to calculate the effect of inhomogeneities in the propagation medium with a relatively small computational effort compared to many other methods (for example, the finite difference method). The boundary element method is first verified by showing agreement with a published result, and then shown to give good agreement with experimental measurements.

\begin{tabular}{|c|c|c|c|c|c|}
\hline 15. SUBJECT TERMS & \multicolumn{2}{|c|}{$\begin{array}{l}\text { Acoustics } \\
\text { Acoustic sensors } \\
\text { BEM }\end{array}$} & $\begin{array}{l}\text { Boundary Element Method } \\
\text { Complex terrain } \\
\text { Inhomogeneous }\end{array}$ & \multicolumn{2}{|c|}{$\begin{array}{l}\text { Outdoor sound } \\
\text { Wave propagation }\end{array}$} \\
\hline \multicolumn{3}{|c|}{ 16. SECURITY CLASSIFICATION OF: } & \multirow{2}{*}{$\begin{array}{l}\text { 17. LIMITATION OF } \\
\text { OF ABSTRACT }\end{array}$} & \multirow{2}{*}{$\begin{array}{l}\text { 18. NUMBER } \\
\text { OF PAGES }\end{array}$} & 19a. NAME OF RESPONSIBLE PERSON \\
\hline a. REPORT & b. ABSTRACT & c. THIS PAGE & & & 19b. TELEPHONE NUMBER (include area code) \\
\hline $\mathrm{U}$ & $\mathrm{U}$ & $\mathrm{U}$ & $\mathrm{U}$ & 22 & \\
\hline
\end{tabular}

